\title{
Analysis of thermal and flow phenomena in natural circulation boiler evaporator
}

\author{
Sławomir Grądziel*
}

\section{A R T I C L E I N F O}

\section{Article history:}

Received 25 September 2018

Received in revised form 24 January 2019

Accepted 1 February 2019

Available online 2 February 2019

\section{Keywords:}

Power boilers

Mathematical model

Energy balance

Waterwall tubes

Boiler evaporator of a natural circulation

\begin{abstract}
A B S T R A C T
An original in-house mathematical model enabling the analysis of thermal and flow phenomena occurring in the evaporator of a natural circulation boiler is proposed herein. It is a distributed parameter model based on an original approach to the problem of solving the equations describing the principles of mass, momentum, and energy conservation. The equations are solved using the method of lines. Space derivatives are written on the left side of the equations and time derivatives are approximated using difference quotients. This system of ordinary differential equations is solved using the Runge-Kutta method. Such an approach is characterised by high stability and accurate calculations. The developed model is applied to obtain the fluid mass flow, pressure, and enthalpy (temperature) values in the boiler evaporator. It can be applied in single- and two-phase flows. This paper presents the original results of the testing of the flow phenomena occurring in the boiler evaporator in steady and transient states. Steady-state tests were performed for different boiler loads. The operating multiplicity of the fluid circulation in the boiler evaporator was determined. A flow meter was installed on a downcomer, which enabled a comparison between the measured values of the water mass flow and those calculated using the developed model. The presented model can also be applied for the analysis of the boiler evaporator operation at an abrupt increase or decrease in pressure in emergency situations. Such occurrences may cause water stagnation in the evaporator tubes; therefore, the tubes may crack.
\end{abstract}

(C) 2019 Elsevier Ltd. All rights reserved.

\section{Introduction}

Issues related to modelling transient thermal and flow phenomena occurring in a natural circulation boiler evaporator are attributed to their complex and strongly nonlinear characteristics in many studies. The complexity results from many factors, such as the high values of temperature and pressure, large surface areas of heating surfaces, the fact that the modelling process has to consider complex heat transfer processes occurring in the furnace chamber, local fouling of the waterwalls, configuration of burners, nonuniform supply of air and fuel to the burner system, and two-phase flow of the medium in the pipes. The nonlinearity is primarily caused by the dependence of the thermal and physical properties of water, steam, and flue gases on pressure and temperature or on temperature only.

The natural circulation of water in the boiler is possible due to the difference between the density of the water-steam mixture in

\footnotetext{
* Corresponding author. The Cracow University of Technology, Institute of Thermal Power Engineering, Al. Jana Pawła II 37, 31-864, Kraków, Poland.

E-mail address: gradziel@mech.pk.edu.pl.
}

the risers and that of the water in the downcomers. This process is referred to as circulation. In large boilers, waterwall tubes (risers) located in heating zones, together with downcomers in nonheating areas with headers, comprise the circulation system or contour. Depending on the location, the circulation contours operate in different thermal load zones. Depending on the boiler design, their number varies from a few to approximately a dozen. The validity of the evaporator operation depends on the device design, quality of assembly, and the conditions in which the device operates.

The validity of water circulation in power boiler evaporators is the subject of numerous studies aiming to ensure the reliability and durability of the boiler components. In other words, their objective is to ensure a continuous and one-way water circulation in the evaporator tubes, ensuring that the evaporator is cooled appropriately.

A simplified lumped mass model of the boiler evaporator was defined previously [1,2]. However, the primary task of these studies is to determine the optimal change in the temperature and pressure of the medium in the boiler evaporator that will shorten the boiler start-up from the cold state.

It is noteworthy that water heaters (economisers), boiler evaporators, and steam superheaters/reheaters with a complex 
structure are still modelled using simple lumped parameter models $[3,4]$ that are intended primarily to satisfy the needs of the boiler automatic systems of regulation. This is due to the intricacies of mathematically distributed parameter models. The advantage of models with lumped thermal parameters is their short computation time; meanwhile, the drawback is that excessive simplifications are made.

Many studies are related to modelling steam superheaters and feed water heaters. Some of them deserve special attention. For example, a distributed parameter model of a steam superheater and the feed water heater was proposed in Refs. [5,6]. The model in Ref. [5] was built using mass, momentum, and energy balance equations. Because the thermal and physical properties of steam, water, and flue gas depend on temperature and pressure, or temperature only, the equations are nonlinear. In Ref. [6], the dynamics of superheaters or economisers is modelled using simplified models based on the energy balance equation, omitting the equations of the balance of mass and momentum. It is noteworthy that the applied mathematical models were verified experimentally by comparing the results of measurements performed on a real facility to those obtained from numerical computations. The models proposed in the studies mentioned above are one dimensional (1D).

Many studies concern the simulations of thermal and flow phenomena occurring in the supercritical boiler furnace chamber waterwalls [7,8]. A distributed parameter mathematical model that enables such simulations is proposed in Ref. [7]. It is a 1D model based on solving the equations describing the principles of mass, momentum, and energy conservation. They are solved using appropriate difference schemes. The model is verified computationally by comparing its results with those obtained from the analytical solution for the transient state. Moreover, a comparison was also performed with the results obtained after solving the balance equations using the Crank-Nicolson method. In both cases, excellent agreement was obtained between the results. The proposed model may also be used as an element of the power unit simulator. A conjugate heat transfer model was proposed in Ref. [8]. A 1D model solution is proposed on the side of the working medium. In the waterwall finned tube, 20 control volumes are separated in each analysed cross section and equations of the threedimensional (3D) transient-state heat transfer are written and solved for them. The results of the developed 1D/3D model are verified by the simulation calculations of the furnace chamber waterwalls installed in a supercritical boiler currently operating in a power station in Poland. Only the single-phase flow is considered in the studies mentioned above, and the results obtained from the simulation are not compared to the measurements.

\section{Literature survey}

The recent literature survey indicates that models of entire boilers or whole sub- and supercritical power plants are available. One example is [9], where Liu et al. developed a model of a 1000MW once-through boiler using neural networks. The model results are compared to those obtained from measurements performed in a real facility. The comparison concerns the output electric power, live steam pressure, and fluid temperature at the separator outlet. It was proven that previously used linear models can well predict the selected working points. However, that effectiveness became worse if the models were used for a real installation in various operating conditions. The obtained results indicate the considerable limitations of linear models in terms of their ability to represent the highly nonlinear characteristics of the power plant dynamics.

A nonlinear approach to the problem of determining the medium enthalpy (temperature) between the water heater inlet and the once-through boiler evaporator outlet is presented in Ref. [10].
The control of steam parameters, such as pressure and temperature, is necessary in power plants to ensure their full reliability. Steam parameters downstream the evaporator and upstream the water heater should be controlled to obtain the required levels of loaddependent nominal values and to ensure that the boiler operates smoothly. This is achieved by controlling the feed water supply to the evaporator inlet and adjusting the mass flow according to the changes in loads. A lumped parameter model of the evaporator is used in Ref. [10]. The model considers the energy balance equation only.

The publications mentioned above concern simulations of the operation of once-through boilers performed using models based on considerable simplifications. One such simplification is by not considering the thermal load nonuniformity along the chamber height or using a lumped parameter model of the evaporator.

Many studies are devoted to the analysis of the waterwall tube operation. Dhanuskodi et al. [11] applied a model using artificial neural networks to determine the temperature of the waterwall tube walls. The model considers the steady-state distributions of pressure and temperature. The nonuniform distribution of loads is also considered. Zheng et al. [12] developed a heat-transfer model in spiral waterwall tubes. It is a distributed parameter model based on the fluid's three-dimensional temperature field, calculated temperature of the wall, mass flow rate (mass flux) distribution, and thermal load of the walls. The same model is proposed in Ref. [13]. Pan et al. [14] developed a model based on mass, momentum, and energy conservation equations. The equations were solved iteratively using the quasi-Newton method, which produced thermo-hydraulic characteristics of the boiler heating surfaces.

Many studies are related to designing general models of entire power plants using commercial computer programs. A model of the dynamics of large power units was developed in Ref. [15]. The APROS software, developed by the VTT Technical Research Centre of Finland in collaboration with the Fortum company, is used for this purpose [16]. APROS includes two thermal hydraulic modules, i.e. the homogeneous and heterogeneous flow model. The homogeneous model is applied for single-phase flows. For two-phase flows (evaporator, condensers), the APROS heterogeneous slip model is used. The high accuracy of the mathematical model applied in the APROS software was confirmed in Refs. [17,18]. The developed model was verified against the power plant operating data.

An integrated model of a boiler in the steady state was developed in Ref. [19]. It is composed of a few submodels, and a modified Newton-Raphson method was used to obtain the numerical solutions of the equations in each submodel. Each heat transfer surface was regarded as a lumped-mass one. The input data for each component of the model, such as temperature, pressure, and mass flow of the medium, were obtained from real installations. The results obtained from the model in steady-state conditions were compared to the real data of a power plant.

Two-phase flows in power boilers have been emphasised significantly in literature, for example in boiler evaporators. Boiler evaporators designed for subcritical parameters are characterised by two-phase flows in the entire range of the power unit loads. In this respect, their operation is different compared to supercritical boilers.

An open natural circulation cycle was proposed in Ref. [20] to design a passive containment cooling system. A numerical code was developed to simulate the process. It is used to analyse the flow characteristic in a small-scale model. The authors proposed a simplified scaling method that was verified through a comparative analysis. The scaling process was divided into heat-transfer scaling in the heat exchanger and pressure-loss scaling in risers and downcomers. The open natural circulation cycle was tested on a laboratory stand. The circulation cycle additionally included a heat 
exchanger. The natural circulation cycle was modelled using simplified mass, momentum, and energy balance equations. A homogeneous model was assumed to calculate the pressure losses in the two-phase flow.

A nonlinear dynamic model of a natural circulation evaporator including a single boiler drum was presented in Ref. [21]. It is a distributed parameter model based exclusively on the fundamental physical laws of mass, momentum, and energy conservation. The presented approach to modelling the boiler operation was based on an analysis of the physical phenomena occurring in the boiler drum, as well as in risers and waterwall tubes. It also considered the boiler's unique design features. The model effectiveness was verified by comparing its results with those obtained from a distributed control system. As a simplification, a lumped parameter model was used for outlet tubes and downcomers. An analysis was conducted to verify the model performance in irregularity conditions in the boiler operation. Special emphasis was placed on the impact of the irregularities on changes in the water level in the boiler drum. The simulation results were compared with the experimental results. Additionally, the simulation results were presented for other key variables of the boiler system that are typically difficult to measure.

A mathematical model based on mass and energy balance equations for the water heater, boiler drum, and superheater was presented in Ref. [22]. The results obtained from the model were compared to those measured in a power plant. The temperature and pressure values at the water heater and boiler drum outlet were analysed. The mean-square error (MSE) was calculated for the comparisons. Analysis was not performed in the studies of evaporator circulation cycle or two-phase flows. The focus was on the parameters of steam at the boiler drum outlet.

It is noteworthy to focus on [23] that presents a mixed model of a power plant operating in combination with a heat recovery steam generator. A simplified model of the boiler drum was used and the water natural circulation in the system was analysed using the SPORTS code developed by Chatoorgoon [24]. A simplified algorithm was applied in the code to analyse a two-phase flow. The results of the proposed model of the boiler dynamics were compared to the results obtained using two other models, i.e. the model developed by Astrom and Bell [25] and that proposed by Bhambare, Mitra, and Gaitonde [26]. The former is a lumped parameter model. The latter is based on the basic equations of mass and energy conservation, and on empirical correlations for twophase flows. Neither of the publications considers or verifies the boiler operation to a greater extent, e.g. during the boiler start-up. The model proposed in Ref. [23] uses distributed parameters, and the analysis concerns are one downcomer and one riser. The mass, momentum, and energy conservation equations are written such that time derivatives are used on their left side, whereas space derivatives are used on the right. The authors suggest that such a nonlinear system of equations should be solved using the available numerical codes. The model validation covers a wide range of boiler operation, i.e. start-ups from cold and the hot states. The results are compared to those obtained using the models described in Refs. [25,26].

\section{Novelty of the present study}

The performed literature survey indicates that no mathematical models can describe the complex transient-state thermal and flow processes occurring in power boiler evaporators with adequate accuracy.

Most studies do not pertain to distributed parameter models the analysis is typically performed using lumped parameter models that are based on different forms of simplifications. Thus far, none have attempted to perform the experimental verification of the mathematical heat-transfer models concerning the evaporator tubes of natural circulation boilers. A detailed analysis of the evaporator (downcomers and risers) operation is still lacking. Therefore, this paper presents a new mathematical model describing the thermal and flow phenomena occurring in the boiler evaporator and the model is verified experimentally.

The proposed distributed parameter model is based on solving balance equations describing the principles of mass, momentum, and energy conservation, and enables an analysis of steady and transient conditions processes. A system of appropriate ordinary differential equations is written with space derivatives on the left side of the equation. The time derivatives on the right-hand side are replaced with backward difference quotients. The system is solved using the Runge-Kutta method. Such an approach is characterised by high computational stability and accuracy. Owing to unique measurements, the developed model of the boiler evaporator enables the determination of the pressure distribution, the mass flow rate and the dryness factor of steam, as well as the water circulation multiplicity in the evaporator.

A flow meter was installed in the downcomer to enable the testing of natural circulation in the boiler evaporator. A series of measurements were performed in a natural circulation boiler with an output of $210 \times 10^{3} \mathrm{~kg} / \mathrm{h}$ to verify the proposed method of modelling transient-state processes occurring in the boiler evaporator. Considering the current requirements related to the steam power boiler operation flexibility, the start-up and shutdown processes and rapid changes in loads, e.g. by opening the turbine valves, should be performed while maintaining the necessary levels of natural circulation. Hence, the measuring points existing in the facility were used. In some cases, some new ones were installed. The measurements were performed during the boiler acceptance tests after a general overhaul. The results obtained during the boiler start-up, shutdown, and steady-state operation were compared to the numerical calculation results.

A novel contribution of the current study is the developed mathematical model, which is characterised by its high stability and accuracy in performing calculations during rapid changes in the boiler load. The results of the presented measurements are also unique.

\section{Mathematical model}

This section presents the method of determining the distribution of the fluid mass flow (mass flux), pressure (pressure drop), and enthalpy (temperature) along the furnace chamber waterwall tube. The relevant mass, momentum, and energy conservation equations are solved. The equations are derived in Ref. [27], and the expressions presented below are their final forms:

- Mass conservation equation:

$\frac{\partial \rho}{\partial \tau}=-\frac{1}{A} \frac{\partial \dot{m}}{\partial z}$

- Momentum balance equation:

$\frac{\partial \dot{m}}{\partial \tau}=-\frac{1}{A} \frac{\partial}{\partial z}\left(\frac{\dot{m}^{2}}{\rho}\right)-A\left(\frac{\partial p}{\partial z}+\frac{\partial p_{f}}{\partial z}+\rho g \sin \varphi\right)$

- Energy balance equation: 
$\frac{\partial h}{\partial \tau}=\left(1-\frac{1}{\rho} \frac{\partial p}{\partial h}\right)^{-1}\left[\frac{\dot{m}}{A \rho}\left(\frac{1}{\rho} \frac{\partial p}{\partial z}-\frac{\partial h}{\partial z}+\frac{1}{\rho} \frac{\partial p_{f}}{\partial z}\right)+\frac{\dot{q} U}{A \rho}-\frac{1}{A \rho} \frac{\partial p}{\partial \rho} \frac{\partial \dot{m}}{\partial z}\right]$

After some simplifications and transformations, the balance equations (1)-(3) can be written in a form where the space derivatives and time derivatives are obtained on the left and right sides of the equations, respectively [27]:

$\frac{\partial \dot{m}}{\partial z}=-A \frac{\partial \rho}{\partial \tau}$

$\frac{\partial}{\partial z}\left(\frac{\dot{m}^{2}}{A^{2} \rho}+p\right)=-\frac{1}{A} \frac{\partial \dot{m}}{\partial \tau}-\frac{\partial p_{f}}{\partial z}-\rho g \sin \varphi$,

$\frac{\partial h}{\partial z}=\frac{\rho A}{\dot{m}}\left(-\frac{\partial h}{\partial \tau}+\frac{\dot{q} U}{A \rho}\right)$

The time derivatives on the right-hand side are replaced with backward difference quotients. This system of ordinary differential equations is solved using the Runge-Kutta method.

After the changes above are introduced, the energy balance equation is of the following form:

$\frac{\mathrm{d} h_{j}^{\tau}}{\mathrm{d} z}=\frac{\rho_{j}^{\tau-\Delta \tau} A}{\dot{m}_{j}^{\tau-\Delta \tau}}\left(-\frac{h_{j}^{\tau}-h_{j}^{\tau-\Delta \tau}}{\Delta \tau}+\frac{\dot{q} U}{A \rho_{j}^{\tau-\Delta \tau}}\right)$

The fluid density is obtained as a function of enthalpy and pressure:

$\rho_{j}^{\tau}=f\left(h_{j}, p_{j}^{\tau-\Delta \tau}\right)$

Solving the mass and momentum conservation equations, the following are obtained, respectively:

$\frac{\mathrm{d} \dot{m}_{j}^{\tau}}{\mathrm{d} z}=-A \frac{\rho_{j}^{\tau}-\rho_{j}^{\tau-\Delta \tau}}{\Delta \tau}$,

$\frac{\mathrm{d}}{\mathrm{d} z}\left(\frac{\left(\dot{m}^{2}\right)_{j}^{\tau}}{A^{2} \rho_{j}^{\tau}}+p_{j}^{\tau}\right)=-\frac{1}{A} \frac{\dot{m}_{j}^{\tau}-\dot{m}_{j}^{\tau-\Delta \tau}}{\Delta \tau}-\frac{d p_{f}}{d z}-\rho_{j}^{\tau} g \sin \varphi$

The changes in the fluid temperature are obtained as a function of enthalpy and pressure:

$t_{j}^{\tau}=f\left(h_{j}^{\tau}, p_{j}^{\tau}\right)$

The subscript ' $j$ ' in equations $7-11$ denotes the subsequent number of analysed cross sections and varies from $j=2 \ldots$ M. All thermophysical properties of the fluid are calculated online. The segment of the fluid flow path from the boiler drum to the downcomers and back to the drum through risers is divided into nodes. The first and last point of the circulation cycle, i.e. 1 and $\mathrm{M}$, are the downcomer and the riser nodes characterised by the same pressure, which is equal to the pressure value in the boiler drum. The equality of pressure in two extreme nodes is obtained iteratively using the Regula-Falsi method.

Moreover, the presented method requires that the Courant condition should be satisfied [28]:

$\Delta \tau \leq \frac{\Delta z}{w}$

The following data were assumed for the computations:
$\Delta \mathrm{z}=0.5 \mathrm{~m}$ and $\Delta \tau=0.02 \mathrm{~s}$

This is a stability condition imposed on the time step to ensure the transposition of the numerical solution with a velocity $\Delta z / \Delta \tau$ higher than the physical velocity $w$.

The flow occurring in a natural circulation boiler evaporator is a single- and a two-phase flow. The friction-related pressure decrease in formula (10) is defined based on the Darcy-Weisbach equation, which is valid for the fluid from the evaporator inlet to the point where the water reaches the saturation temperature:

$\frac{d p_{f}}{d z}=\frac{f}{d_{\text {in }}} \frac{\dot{m}|\dot{m}|}{2 \rho A^{2}}$

where:

$d_{\text {in }}$ - inner diameter of a duct with a circular cross section or equivalent diameter,

$f-$ friction factor.

The friction factor is extremely difficult to determine in a mixture of water and steam. A number of mathematical models have been proposed to find the component being the effect of friction. The flow of the mixture can be considered as homogeneous, or a slip flow model can be applied. Different models of determination of pressure losses in two-phase flows are presented in Ref. [29], and the obtained results are compared to each other.

The use of the homogenous model involves assuming that the properties of the fluid are averaged for the entire mixture. Another assumption is that the velocity values of the gaseous and the liquid phase are the same, which implies that there is no slip between the phases. For the homogeneous model, the decrease in pressure due to friction is defined by the following equation:

$\frac{d p_{f}}{d z}=\frac{f_{T P}}{d_{\text {in }}} \frac{G^{2}}{2 \rho_{T P}}$

where:

$f_{T P}-$ two-phase friction factor,

$G-$ mass flux, $\mathrm{kg} /\left(\mathrm{m}^{2} \mathrm{~s}\right)$,

$\rho_{T P}-$ two-phase density, $\mathrm{kg} / \mathrm{m}^{3}$.

Classical relations, such as the Blasius formula, are used to determine the friction factor. In this case, the Reynolds number obtained for the averaged properties of the mixture is applied [30,31]:

$\operatorname{Re}_{T P}=\frac{G \cdot d_{i n}}{\eta_{T P}}$

where

$\frac{1}{\eta_{T P}}=\frac{x}{\eta_{G}}+\frac{1-x}{\eta_{L}}$

where:

$\eta_{T P}, \eta_{G}, \eta_{L}$ - dynamic viscosity of the homogenous mixture, the gaseous phase and the liquid phase, respectively, $\mathrm{x}$ - dryness factor.

The two-phase mixture density is obtained using the following formula: 
$\rho_{T P}=\frac{\rho_{L} \cdot \rho_{G}}{x \rho_{L}+(1-x) \rho_{G}}$

where:

$\rho_{G}, \rho_{L}-$ density of the gaseous and the liquid phase, respectively.

Using slip models involves calculating the two-phase flow multiplier that enables the friction-related pressure decrease to be obtained. The concepts included in this group are the Lockhart-Martinelli model, Friedel model, Chisholm model, and Martinelli-Nelson graphical method [31].

\section{- The Lockhart-Martinelli model}

To apply the Lockhart-Martinelli model the two-phase multipliers should be found. It makes it possible to determine the pressure gradient caused by frictional losses arising in the flow of the mixture [31]:

$\frac{d p_{T P}}{d z}=\phi_{L}^{2} \frac{d p_{L}}{d z}$

The following formula is used to define the two-phase multiplier used in equation (18):

$\phi_{L}^{2}=1+\frac{C}{X}+\frac{1}{X^{2}}$

The Martinelli parameter $X$ appears in equation (19). It is defined as

$X=\left(\frac{1-x}{x}\right)^{0.9}\left(\frac{\rho_{G}}{\rho_{L}}\right)^{0.5}\left(\frac{\eta_{L}}{\eta_{G}}\right)^{0.1}$

The determination of the Lockhart-Martinelli multiplier is related to establishing the flow character of individual phases. The parameter $C$ is selected depending on whether the flow of the phases is laminar or turbulent (cf. Table 1 ).

The Friedel model was built using 25,000 measuring points. The model is applied for two-phase flows in vertical and horizontal tubes. The following formula is used to determine the two-phase multiplier [31]:

$\phi_{L O}^{2}=E+\frac{3.24 F H}{F r^{0.045} W e^{0.035}}$

Two-phase multiplier $\phi_{L o}^{2}$ is related to the flow of a mixture with properties related to the properties of the liquid phase. Coefficients $E, F$ and $H$, as well as the Froude number $(F r)$ and the Weber number $(W e)$ in formula (21) are described in Ref. [31].

The Friedel model is recommended if the ratio between the liquid and gaseous phase dynamic viscosity is $\left(\eta_{\mathrm{L}} / \eta_{\mathrm{G}}\right) \leq 1000$. If the condition is satisfied, equation (21) may be used in the entire range of the steam dryness factor values.

- The Chisholm Model

Table 1

Values of parameter $\mathrm{C}$.

- The Friedel model

\begin{tabular}{lll}
\hline Liquid & Gas & $\mathrm{C}$ \\
\hline turbulent & turbulent & 20 \\
viscous & turbulent & 12 \\
turbulent & viscous & 10 \\
viscous & viscous & 5 \\
\hline
\end{tabular}

The Chisholm model is empirical. It can be used for a wide range of values of the dryness factor and steam pressure. The following relation is used to define the two-phase multiplier [31]:

$\phi_{L O}^{2}=1+\left(Y^{2}-1\right)\left[B x^{0.5(2-n)}(1-x)^{0.5(2-n)}+x^{2-n}\right]$,

where:

$\mathrm{Y}^{2}$ - the ratio between pressure gradients of the gaseous and the liquid phase in single-phase flows

$\mathrm{B}$ - mass flow rate (mass flux)-dependent coefficient

$\mathrm{n}$ - exponent defining the coefficient of the flow resistance. For the Blasius formula, $\mathrm{n}=0.25$.

The methods of finding parameters $\mathrm{Y}^{2}$ and $\mathrm{B}$ are presented in Ref. [31].

- The Martinelli-Nelson graphical method

The Martinelli-Nelson method was developed based on flows of the mixture of steam and water through horizontal pipes at pressure values ranging from 0.689 to $20.7 \mathrm{MPa}$. The two-phase multiplier needed to determine the losses arising due to friction is read from a chart developed using different steam pressures and different values of the dryness factor $(x)$ (cf. Fig. 1 ). If pressure gets higher than the water critical point, the multiplier is $\phi_{L o}^{2} \approx 1$ [32]. The two-phase multiplier read from the chart makes it possible to

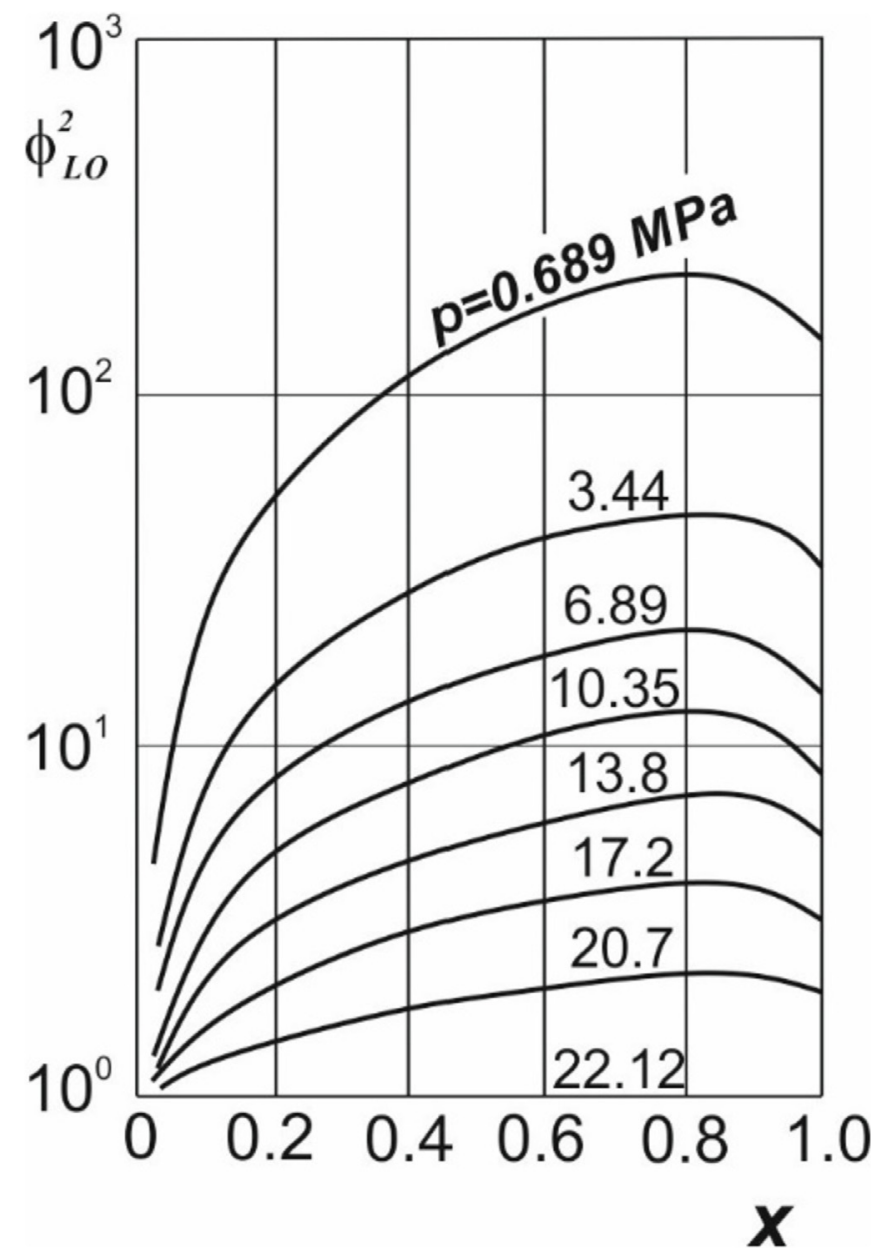

Fig. 1. Martinelli-Nelson correlation [33]. 
determine the frictional decrease in pressure using the following relation:

$\frac{d p_{f}}{d z}=\phi_{L O}^{2} \frac{d p_{f, L O}}{d z}$

where.

$\frac{d p_{f . L O}}{d z}$ - friction-related losses in the flow of a two-phase mixture characterised by properties related to the liquid phase properties, $\mathrm{Pa} / \mathrm{m}$.

\section{Experimental verification}

This section presents the experimental verification of the developed model. First, the values of frictional losses arising in a $210 \times 10^{3} \mathrm{~kg} / \mathrm{h}$ boiler waterwall tube and calculated using the homogenous and the phase slip models presented herein are compared. The experimental verification consists of comparing the calculated and measured values of the water mass flow in the downcomers and in obtaining the dryness factor and circulation multiplicity. The numerical computations were performed using in-house programs written in the Fortran language [34].

The water mass flow rate in the downcomer was measured in a boiler with the output of $210 \times 10^{3} \mathrm{~kg} / \mathrm{h}$. It is a single-drum natural circulation boiler (cf. Fig. 2). The boiler generates high-pressure

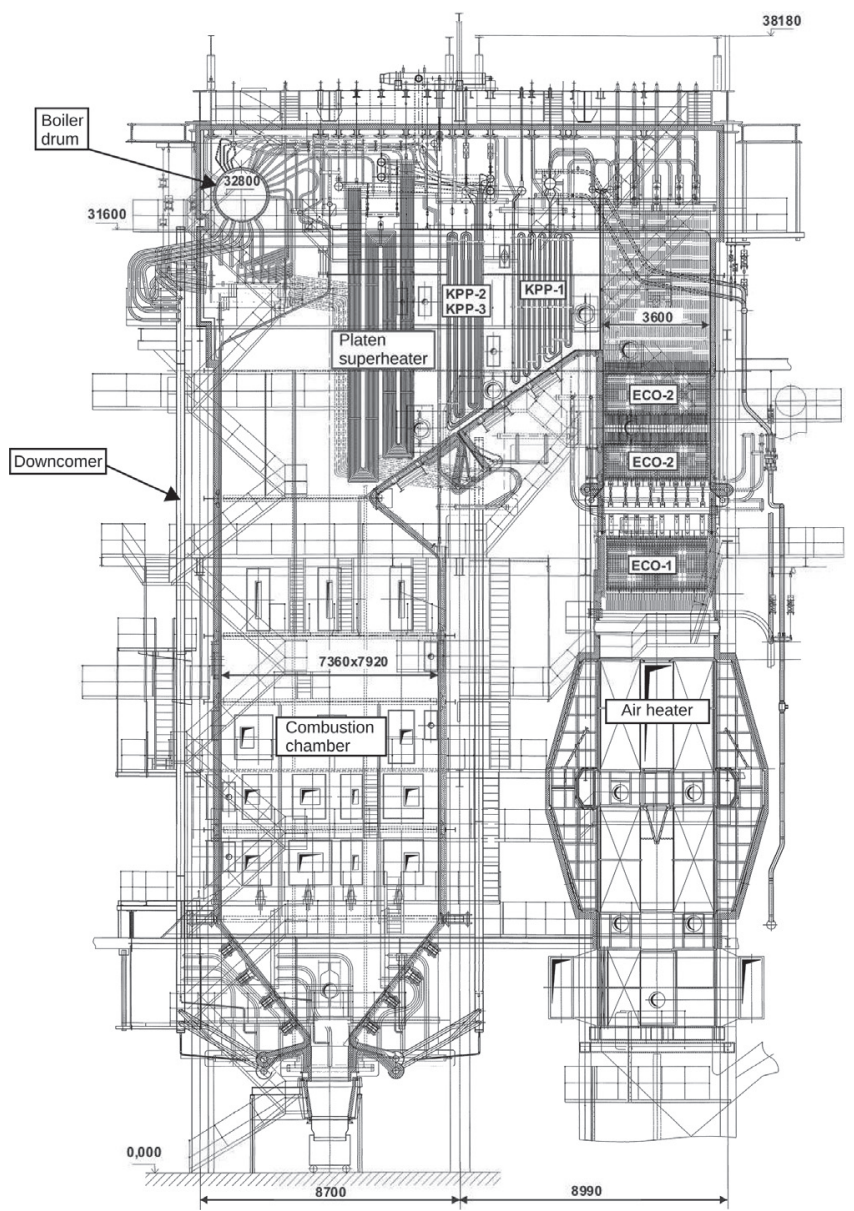

Fig. 2. Diagram of the analysed natural circulation boiler with the output of $210 \times 10^{3} \mathrm{~kg} / \mathrm{h}$; KPP-1 - first stage of the steam superheater; KPP-2 - second stage of the steam superheater; KPP-3 - third stage of the steam superheater; ECO- 1 - first stage of the economizer; ECO-2 - second stage of the economizer. superheated steam fed into the power plant's primary duct. The boiler rated output totals $210 \times 10^{3} \mathrm{~kg} / \mathrm{h}$ at the steam outlet pressure of $9.8 \mathrm{MPa}$ and temperature of $540^{\circ} \mathrm{C}$. The platen superheater and the following stages of the steam superheaters are located in the combustion gas bridge: 1st stage (KPP-1), 2nd stage (KPP-2) and 3rd stage (KPP-3). The two stages of the economizer (ECO-1 and ECO-2), and a tubular-type air heater are placed in the convective section. For verification, the boiler evaporator operation was analysed during start-up, in the steady-state mode, and also during the boiler acceptance tests. The acceptance tests were made prior to the boiler re-commissioning after a general overhaul.

The steam-water system of the boiler evaporator comprises a drum, downcomers, risers, pipelines with fittings, and measuring instruments. The boiler water flows from the drum into 10 $\varnothing 273 \times 25$ downcomers through $54 \varnothing 108 \times 10$ tubes and continues through four $\varnothing 130 \times 10$ tubes to reach the waterwall tubes. Having passed through the waterwall tubes, the steam-water mixture flows into the drum through $\varnothing 76 \times 10$ tubes.

Fig. 3 presents a diagram of the analysed boiler circulation contour with a marked point of the water mass flow measurement in the downcomer. The meter was installed at a height of approximately $10 \mathrm{~m}$. The method of meter fixing in the tube was described in Ref. [35]. The boiler water was transferred from the drum through five $\varnothing 108 \times 10$ tubes to a $\varnothing 273 \times 25$ downcomer; subsequently, from flowing through three $\varnothing 130 \times 10$ tubes, it reaches into the header followed by $30 \varnothing 60 \times 5$ waterwall tubes. Twelve $\varnothing 76 \times 10$ tubes carried the steam-water mixture into the drum.

The distribution of the thermal load along the waterwall tubes

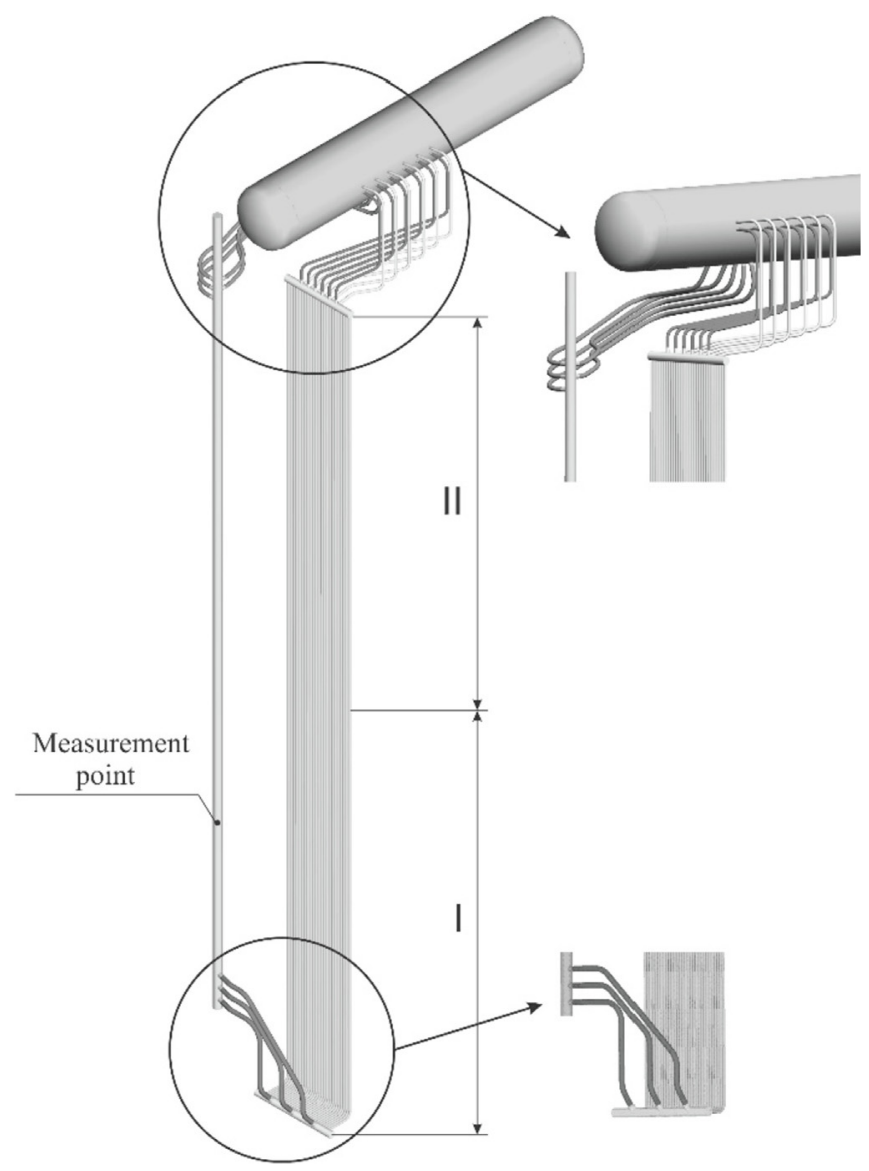

Fig. 3. Diagram of the boiler evaporator with a marked point of the water mass flow measurement. 
was calculated using the zone method. Details of the calculation method are presented in Ref. [36]. The height-dependent load of the furnace chamber walls adopted for the calculations, for the boiler output of $210 \times 10^{3} \mathrm{~kg} / \mathrm{h}$, is shown in Fig. 4 .

The saturation temperature is reached and the boiler water partially evaporates in the waterwall tubes. To compare the frictional losses, the calculation methodology is typically based on the evaporator division into a few zones [37]. In this study, the waterwall tubes are divided into two evaporation zones (cf. Fig. 3) [29]. At the first and second zone outlets, the steam dryness factors are $\mathrm{x}=0.04$ and $\mathrm{x}=0.1$, respectively. An increase in the dryness factor value involves an increase in frictional losses. The comparison between the resistances obtained using the homogenous and phase slip models is presented in Table 2.

The calculation results indicate that the friction-related pressure decreases are of similar values for most of the models. Some differences occur for the Lockhart-Martinelli model, which was developed based on the flow measurements of air-water and air-oil mixtures. The share of frictional pressure losses in the overall pressure drop is relatively small. Hence, the selection of model to determine friction-related pressure losses is irrelevant the selection has little impact on the total pressure drop in the circulation contour of natural circulation boilers. Further, in equation (10), the frictional losses are calculated using the homogeneous model.

Figs. 5-7 present the measurement results and the results of the calculations performed during the boiler start-up. Fig. 5 shows a curve illustrating the measured changes in the steam pressure in the drum (saturation pressure).

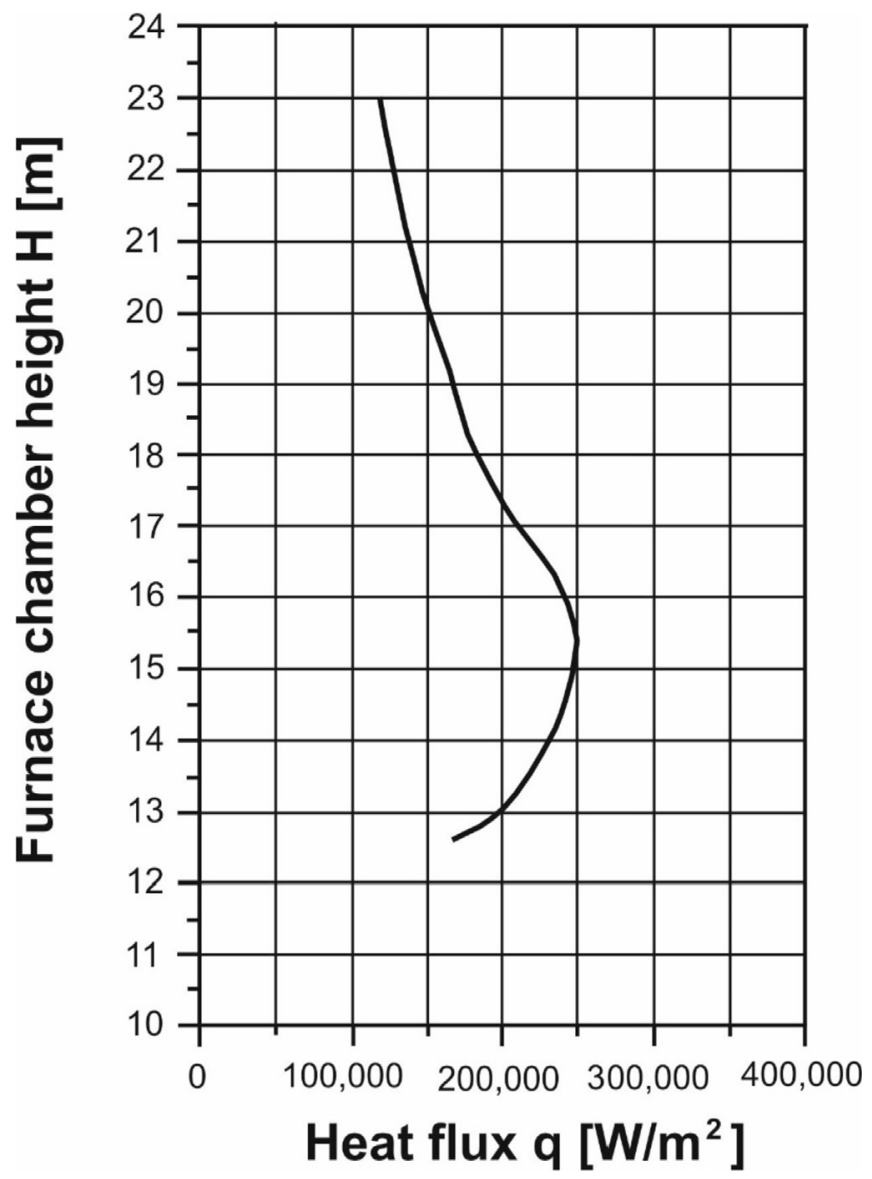

Fig. 4. Distribution of front waterwall thermal load along the furnace chamber height for the boiler output of $\dot{m}=210 \times 10^{3} \mathrm{~kg} / \mathrm{h}$.
Table 2

Comparison of results.

\begin{tabular}{|c|c|c|c|c|c|}
\hline \multirow[t]{2}{*}{ Section } & \multicolumn{5}{|c|}{ Frictional losses, $\mathrm{Pa} / \mathrm{m}$} \\
\hline & 1 & 2 & 3 & 4 & 5 \\
\hline I & 174 & 318 & 211 & 194 & 110 \\
\hline II & 260 & 968 & 375 & 348 & 396 \\
\hline
\end{tabular}

1 - homogeneous model, 2 - Lockhart-Martinelli model, 3 - Friedel model, 4 Chisholm model, 5 - Martinelli-Nelson model.

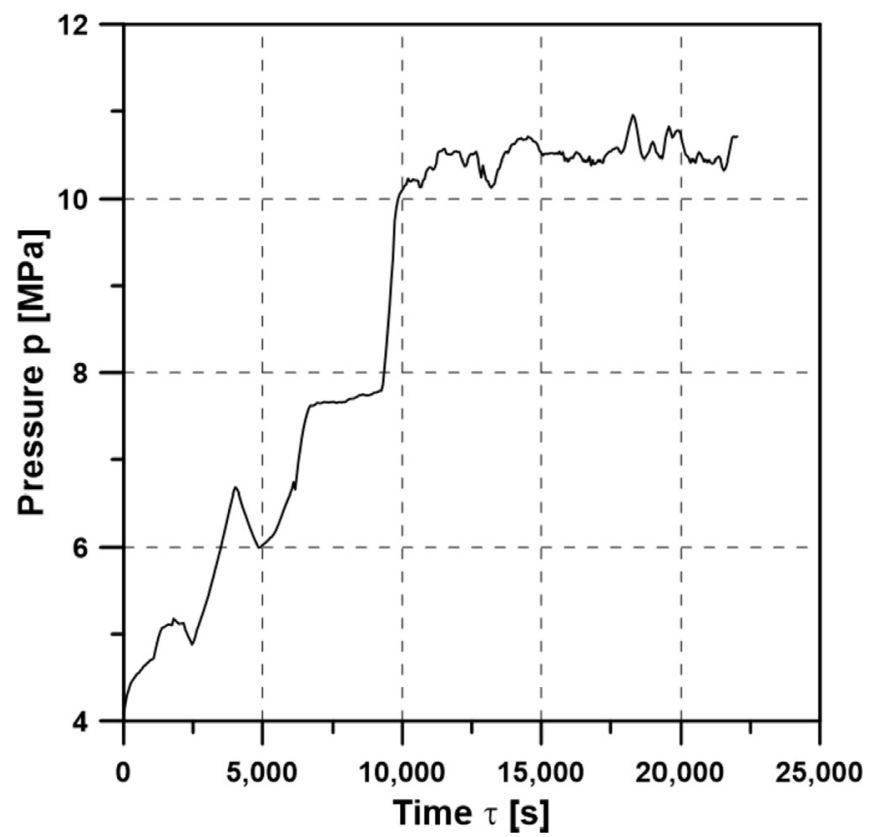

Fig. 5. Curve illustrating changes in pressure measured in the drum during start-up.

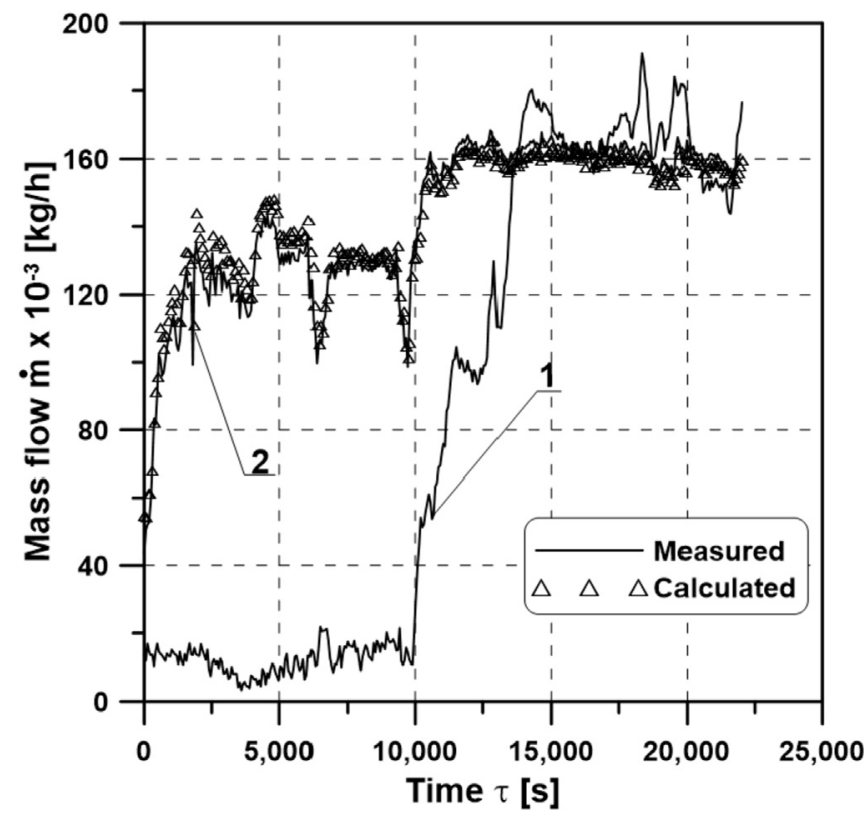

Fig. 6. Changes in mass flow over time: 1 - the boiler steam output, 2 - comparison between the measured and calculated values of the boiler water mass flow in the downcomer. 


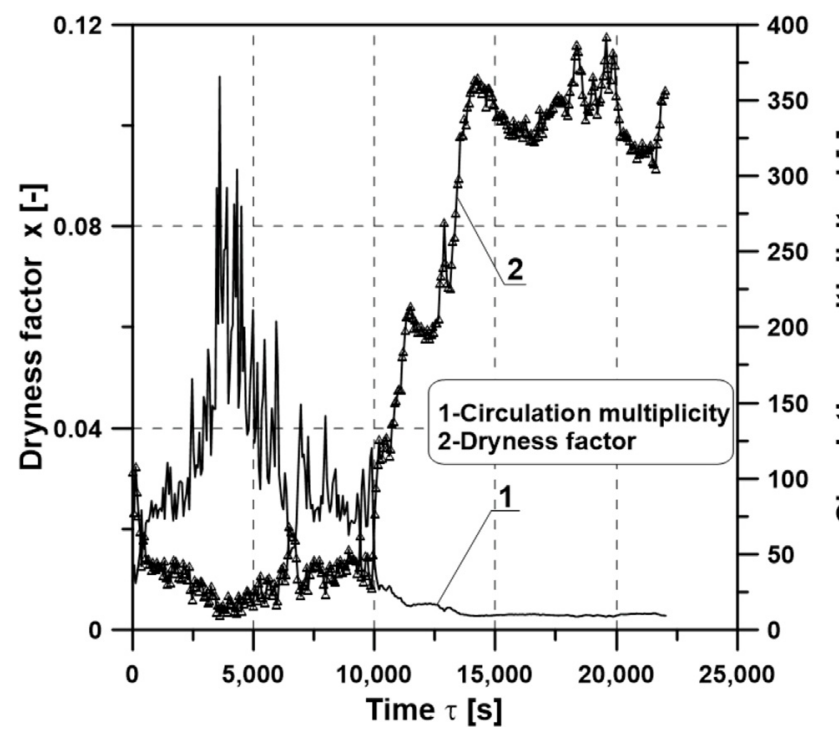

Fig. 7. Calculated circulation multiplicity and the steam-water mixture dryness factor.

Fig. 6 presents the boiler steam output (Curve 1) and a comparison of the measured and calculated values of the mass flow in the downcomer (Curves 2). The error between the results of the measurements and calculations is $\mathrm{MSE}=5.753$ (Table 3). It may therefore be stated that the agreement between the results is satisfactory, considering the fact that they relate to the boiler transient operation during start-up. The performance of the proposed mathematical model at such rapid changes is stable.

Fig. 7 presents the determined circulation multiplicity and the dryness factor of the steam-water mixture flowing into the drum. As shown in Fig. 7, a certain instability occurs in the circulation multiplicity ( $j \approx 350$ in time $3000-4000$ s); this could be due to the small amount of generated steam at the beginning of the boiler operation. It is only after the boiler achieves the steady-state operation mode (after approximately 12,000-15,000 s) that the circulation multiplicity stabilises at 8.5-9.5.

Figs. 8-10 show the results of the measurements and calculations performed for the boiler operation under variable loads (acceptance tests). During the boiler acceptance tests, the boiler steam output was decreased from $180 \times 10^{3} \mathrm{~kg} / \mathrm{h}(50 \mathrm{~kg} / \mathrm{s})$ to approximately $150 \times 10^{3} \mathrm{~kg} / \mathrm{h} \quad(41.7 \mathrm{~kg} / \mathrm{s})$ and subsequently increased to approximately $200 \times 10^{3} \mathrm{~kg} / \mathrm{h}(55.6 \mathrm{~kg} / \mathrm{s})$.

The measurements continued for a period of approximately $22 \mathrm{~h}$. The changes in the drum pressure are illustrated in Fig. 8. Fig. 9 presents the results of the boiler steam output measurements (Curve 1) and the comparison between the measured and calculated values of the boiler water mass flow in the downcomer (Curve 2 ). In this case, the error between the results of the measurements and the calculations is MSE $=1.862$ (Table 3). The result is fully satisfactory. The computational algorithm remains stable during long periods of the boiler operation $(\tau=80,000 \mathrm{~s})$. Towards the end of the measurements (from the time of $\tau \sim 64,000 \mathrm{~s}$ ), at a significant change in the steam mass flow at the boiler outlet from $\sim 160 \times 10^{3} \mathrm{~kg} / \mathrm{h}$ to $210 \times 10^{3} \mathrm{~kg} / \mathrm{h}$, slight differences between the

Table 3

Mean-square error.

\begin{tabular}{llll}
\hline & \multicolumn{2}{l}{ Mass flow rate } & \\
\cline { 2 - 4 } & Fig. 6 & Fig. 9 & Fig. 12 \\
\hline MSE & 5.753 & 1.862 & 0.237 \\
\hline
\end{tabular}

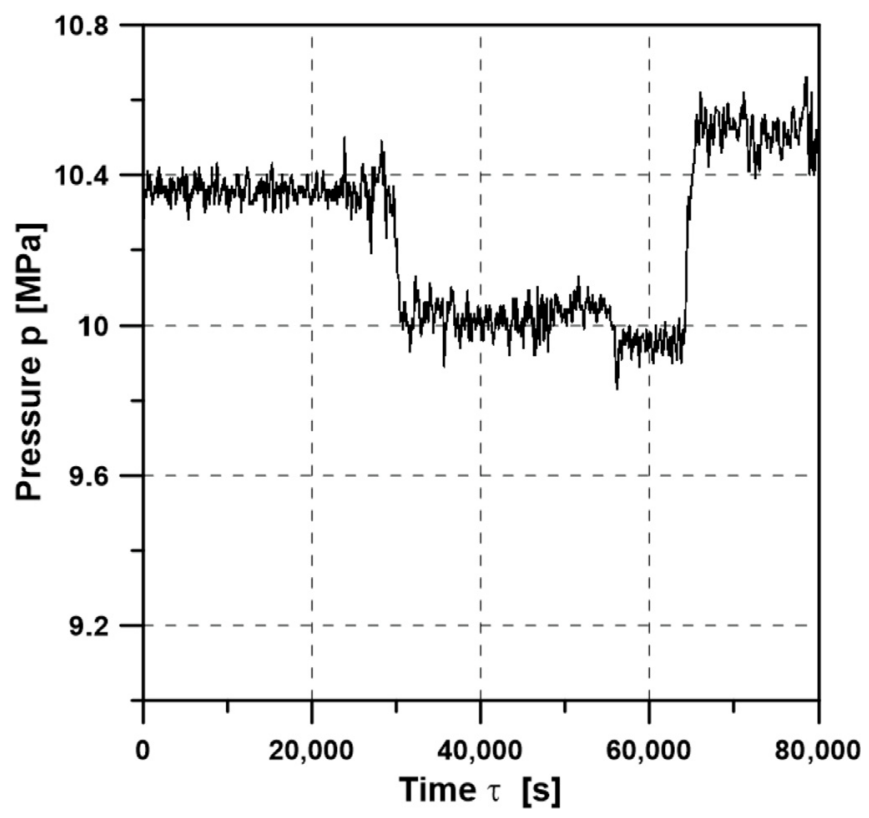

Fig. 8. Curve illustrating changes in pressure measured in the drum during the boiler operation under a changing load.

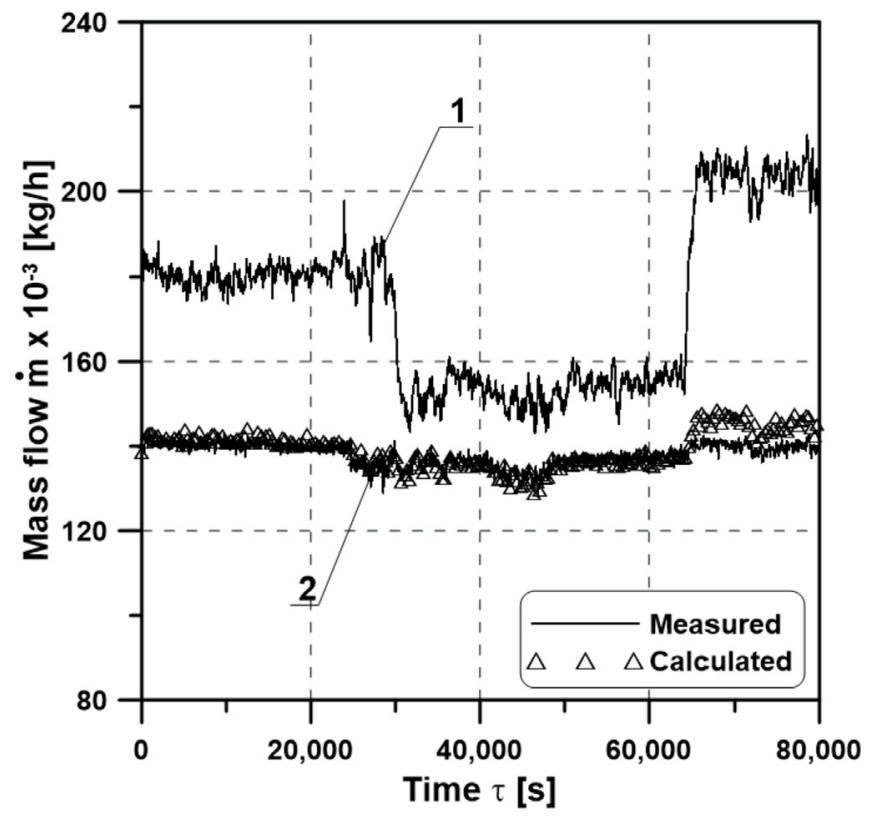

Fig. 9. Changes in the mass flow over time: 1 - the boiler steam output, 2 - comparison between the measured and calculated values of the boiler water mass flow in the downcomer.

results can be observed. Fig. 10 presents the determined circulation multiplicity and the steam-water mixture dryness factor.

As shown in Fig. 10, regardless of the load, the flow in the downcomer was stable; only the circulation multiplicity varied within the range of $j=7-9.5$. In the time interval of ( $\tau=0-30,000 \mathrm{~s}$ ) the boiler pressure totals $10.4 \mathrm{MPa}$ (cf. Fig. 8), corresponding to a circulation multiplicity of approximately $j=8$. If the boiler drum pressure is decreased to the value of approximately $p=10 \mathrm{MPa}(\tau=30,000-63,000 \mathrm{~s})$, the circulation multiplicity is approximately $j=9.5$. In the last interval of the boiler testing at $\tau=63,000-80,000 \mathrm{~s}$, the pressure measured in the boiler drum is 


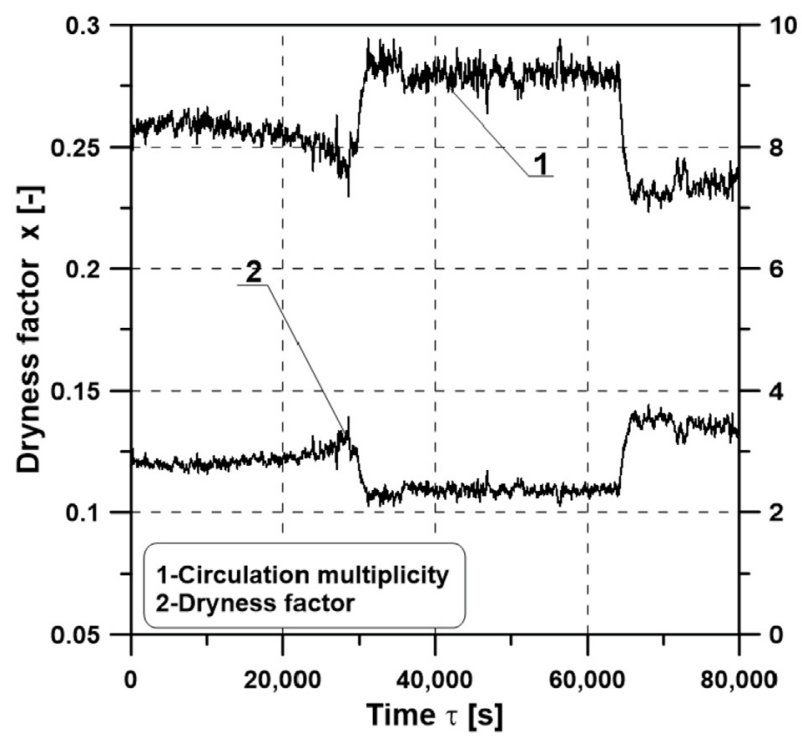

Fig. 10. Calculated circulation multiplicity and the steam-water mixture dryness factor.

$p=10.5 \mathrm{MPa}$ (cf. Fig. 8), and the circulation multiplicity value decreases to the level of approximately $j=7$. From the boiler operation described above and the results obtained from the measurements and calculations, the proposed model responds rapidly to load variations and demonstrates good computational stability. The rapid changes illustrated by the curves presented in Figs. 8-10 remained for approximately $22 \mathrm{~h}(80,000 \mathrm{~s})$.

Figs. 11-13 present the results of the measurements and calculations performed during the boiler steady-state operation. The boiler steam output ranges from $160 \times 10^{3} \mathrm{~kg} / \mathrm{h}$ to $190 \times 10^{3} \mathrm{~kg} / \mathrm{h}$ $(44.4-52.8 \mathrm{~kg} / \mathrm{s})$ for the period of approximately $5.5 \mathrm{~h}(20,000 \mathrm{~s})$ (cf. Fig. 12 - Curve 1).

Fig. 11 shows the curve illustrating changes in the pressure in the drum, and Fig. 12 presents a comparison between the results

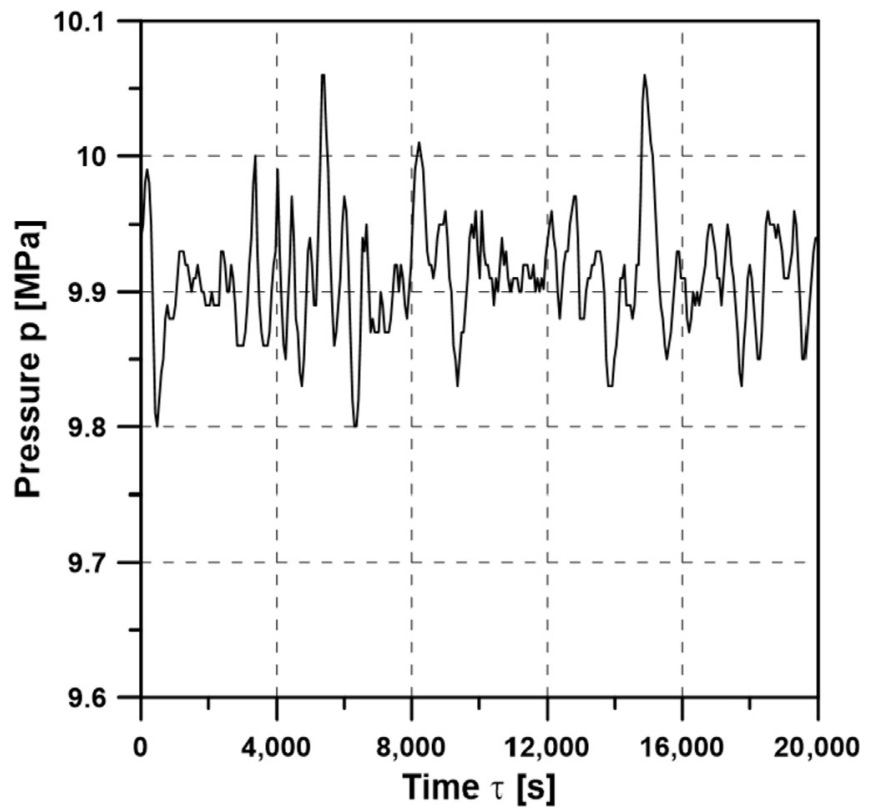

Fig. 11. Curve illustrating changes in pressure measured in the drum during the boiler steady-state operation.

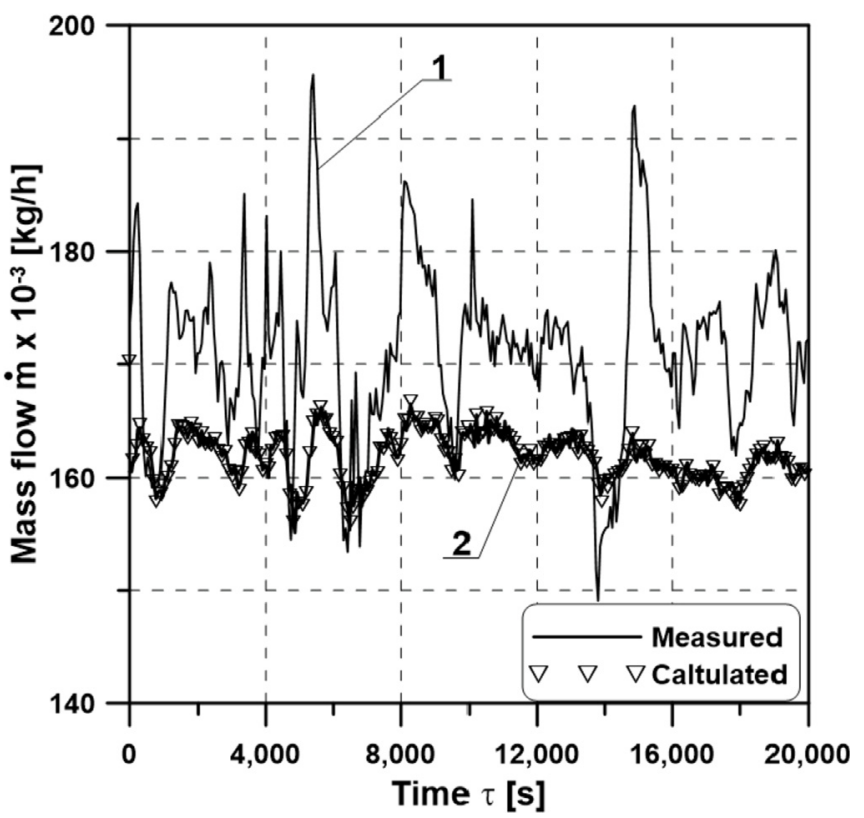

Fig. 12. Changes in mass flow over time: 1 - the boiler steam output, 2 - comparison between the measured and calculated values of the boiler water mass flow in the downcomer.

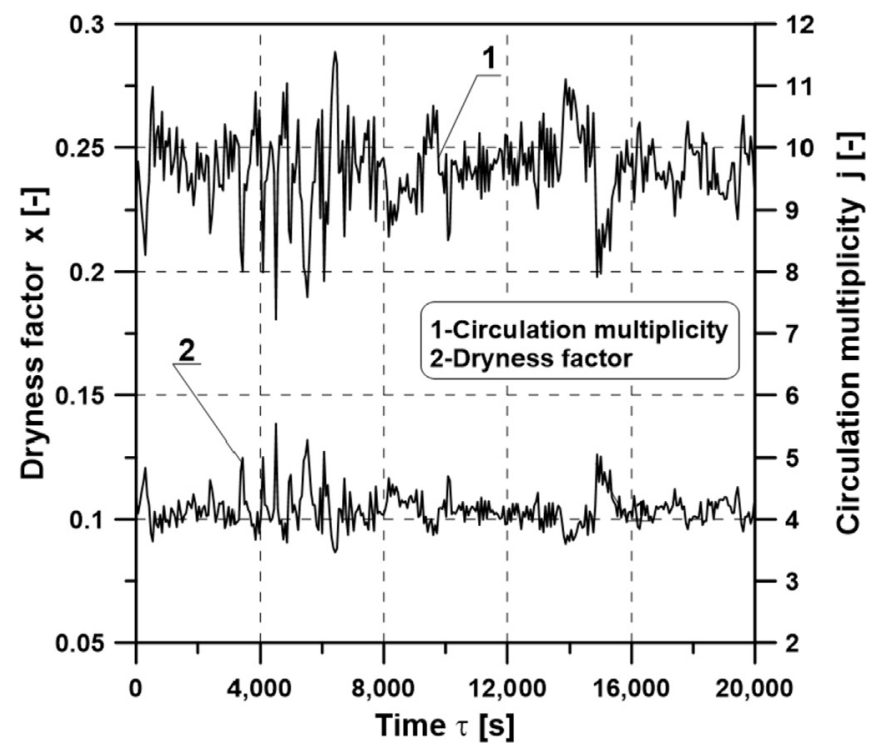

Fig. 13. Calculated circulation multiplicity and the steam-water mixture dryness factor.

obtained from the water mass flow measurements and calculations (Curves 2). The error between the results of the measurements and the calculations is MSE $=0.237$ (Table 3 ). In this case, the result is excellent. During the boiler steady-state operation, the proposed mathematical model is highly stable and demonstrates high computational accuracy.

Fig. 13 presents the determined circulation multiplicity and the dryness factor. As shown in Fig. 13, during the boiler steady-state operation, the obtained mean circulation multiplicity totals $\mathrm{j}=9.8$ at the boiler drum mean pressure value of $\mathrm{p}=9.92 \mathrm{MPa}$. The circulation multiplicity value calculated for this pressure corresponds to the multiplicity occurring in real facilities.

To determine the effectiveness of the method, the mean-square 
error is calculated. The MSEs for the performed calculations and measurements were determined using the following relation:

$M S E=\sqrt{\frac{1}{n} \sum_{i=1}^{n}\left(y_{i}-y_{d t}\right)^{2}}$

where.

$\mathrm{n}$ - number of measurements; $\mathrm{y}_{\mathrm{i}}-$ measured value; $\mathrm{y}_{\mathrm{dt}}-\mathrm{ex}-$ pected (calculated) value.

The results were obtained from the calculations in Table 3.

The proposed model can be a useful tool for online monitoring the thermal and flow processes occurring in the boiler pressure elements. It enables circulation control in the evaporator to prevent water stagnation in the boiler risers during fast changes in loads. Apart from monitoring flows through tubes, it is also possible to control the thermal processes occurring in the furnace chamber. Such a system, using the presented model and water flow measurements in the boiler downcomers, is installed in a power plant in Poland. The start-up process is performed and controlled such that the appropriate levels of circulation in the evaporator are ensured, thus enabling the levels to exceed the thermal stresses arising in the boiler thick-walled elements. The developed model can also be implemented in other steam-generating units in the range of sub- and supercritical pressure values.

\section{Conclusions}

The strict control of boiler evaporator operation is becoming increasingly important. Therefore, there has been strong motivation and growing interest towards the development of a mathematical model that can simulate the boiler evaporator performance not only at the boiler constant load, but also in a wide range of dynamic changes including start-ups and varying loads.

A mathematical model enabling the simulations of thermal and flow phenomena occurring in the evaporator of a natural circulation boiler was presented herein. It is a distributed parameter model based on solving the equations describing the principles of mass, momentum, and energy conservation. As proposed herein, the balance equations were solved using the Runge-Kutta method.

The analysis of the calculations of friction-related losses performed in this study using different models enabled the differences between the obtained results to be observed. The differences were the effect of the different approaches to the two-phase flow multiplier determination. In the analysed conditions of the twophase flow in the natural circulation boiler evaporator, considering the evaporator pressure, the circulation multiplicity was high $(j \approx 10)$; consequently, the dryness factor of the steam-water mixture at the drum inlet was small. This implied that in this type of flow, the friction-related pressure decrease was significantly smaller than the sum of the two other quantities comprising the total pressure decrease, i.e. the sum of the hydrostatic pressure drop and the decrease resulting from the change in the two-phase mixture momentum. In this situation, the accuracy of the method of the friction-related constituent determination is negligible. In this study, frictional pressure losses in the two-phase flow were determined using a homogenous model.

The developed method was verified experimentally. The natural circulation in the evaporator of a boiler with the steam output of $210 \times 10^{3} \mathrm{~kg} / \mathrm{h}$ was tested. The tests were performed during the boiler start-up and shutdown, and during the boiler steady-state operation. The calculation results were compared to the measurement results, and a fully satisfactory agreement was obtained.
The developed mathematical model can be used to simulate thermal and flow phenomena occurring in both evaporators of natural circulation boilers and supercritical once-through boilers.

\section{References}

[1] Taler J, Węglowski B, Taler D, Sobota T, Dzierwa P, Trojan M, Madejski P, Pilarczyk M. Determination of start-up curves for a boiler with natural circulation based on the analysis of stress distribution in critical pressure components. Energy 2015;92:153-9.

[2] Taler J, Dzierwa P, Taler D, Harhut P. Optimization of the boiler start-up taking into account thermal stresses. Energy 2015;92:160-70.

[3] Chaibakhsh A, Ghaffari A, Moosavian SAA. A simulated model for a oncethrough boiler by parameter adjustment based on genetic algorithms. Simulat Model Pract Theor 2007;15:1029-51.

[4] Li H, Huang X, Zhang L. A lumped parameter dynamic model of the helical coiled once-through steam generator with movable boundaries. Nucl Eng Des 2008;238:1657-63.

[5] Zima W. Simulation of dynamics of a boiler steam superheater with an attemperator. Proc IME J Power Energy 2006;220:793 $\div 801$.

[6] Zima W. Mathematical modelling of transient processes in convective heated surfaces of boilers, Forschung im Ingenieurwesen, vol. 71. Springer Verlag; 2007. p. $113-23$.

[7] Zima W, Nowak-Ocłoń M, Ocłoń P. Simulation of fluid heating in combustion chamber waterwalls of boilers for supercritical steam parameters. Energy 2015;92:117-27.

[8] Zima W, Nowak-Ocłoń M. Novel online simulation-ready models of conjugate heat transfer in combustion chamber waterwall tubes of supercritical power boilers. Energy 2018;148:809-23.

[9] Liu XJ, Kong XB, Hou GL, Wang JH. Modeling of a 1000 MW power plant ultra super-critical boiler system using fuzzy-neural network methods. Energy Convers Manag 2013;65:518-27.

[10] Backi ChJ. Nonlinear modeling and control for an evaporator unit. Contr Eng Pract 2018;78:24-34

[11] Dhanuskodi R, Kaliappan R, Suresh S, Anantharaman N, Arunagiri A, Krishnaiah J. Artificial Neural Networks model for predicting wall temperature of supercritical boilers. Appl Therm Eng 2015;90:749-53.

[12] Zheng S, Luo Z, Zhou H. Distributed parameter modeling and thermal analysis of a spiral water wall in a supercritical boiler. Therm Sci 2013;17:1337-42.

[13] Shu Z, Zixue L, Yanxiang D, Huaichun Z. Development of a distributedparameter model for the evaporation system in a supercritical W-shaped boiler. Appl Therm Eng 2014;62:123-32.

[14] Pan J, Wu G, Yang D. Thermal-hydraulic calculation and analysis on water wal system of 600 MW supercritical CFB boiler. Appl Therm Eng 2015;82:225-36.

[15] Starkloff R, Alobaid F, Karner K, Epple B, Schmitz M, Boehm F. Development and validation of a dynamic simulation model for a large coal-fired power plant. Appl Therm Eng 2015;91:496-506.

[16] VTT. APROS simulation software. Available from: http://www.apros.fi.

[17] Alobaid F, Starkloff R, Pfeiffer S, Karner K, Epple B, Hyun-Gee Kim. A comparative study of different dynamic process simulation codes for combined cycle power plants - part A: part loads and off-design operation. Fuel 2015;153:692-706.

[18] Alobaid F, Starkloff R, Pfeiffer S, Karner K, Epple B, Hyun-Gee Kim. A comparative study of different dynamic process simulation codes for combined cycle power plants - part B: start-up procedure. Fuel 2015;153: 707-16.

[19] Hajebzadeh H, Ansari Abdulhamid NM, Niazi S. Mathematical modeling and validation of a 320MW tangentially fired boiler: a case study. Appl Therm Eng 2019;146:232-42.

[20] Guoa X, Sun Z, Wang J, Yu S. Scaling analyses for the open flashing-driven natural circulation system. Nucl Eng Des 2017;324:111-21.

[21] Sedić A, Katulić S, Pavković D. Dynamic model of a natural water circulation boiler suitable for on-line monitoring of fossil/alternative fuel plants. Energy Convers Manag 2014;87:1248-60.

[22] Sreepradha Chandrasekharan, Chandra Panda Rames, Swaminathan Bhuvaneswari Natrajan. Mathematical model for integrated coal fired thermal boiler using physical laws. Energy 2017;118:985-98.

[23] Sunil PU, Barve Jayesh, Nataraj PSV. Mathematical modeling, simulation and validation of a boiler drum: some investigations. Energy 2017;126:312-25.

[24] Chatoorgoon V. SPORTS - a simple non-linear thermalhydraulic stability code. Nucl Eng Des 1986;93(1):51-67.

[25] Astrom KJ, Bell RD. Drum-boiler dynamics. Automatica 2000;36:363-78.

[26] Bhambare KS, Mitra SK, Gaitonde UN. Modeling of a coal-fired natural circulation boiler. J Energy Resour Technol 2007;129(2):159-67.

[27] Grądziel S, Majewski K. Simulation of heat transfer in combustion chamber waterwall tubes of supercritical steam boilers. Chem Process Eng 2016;37(No. 2):199-213.

[28] Gerald CF, Wheatley PO. Applied numerical analysis. California Polytechnic State University, Addison-Wesley Publishing Company; 1994.

[29] Gradziel S, Majewski K. Calculations of the pressure drop in the natural circulation boiler evaporator. In: MATEC web of conferences, vol. 240; 2018 https://doi.org/10.1051/matecconf/201824005009. 05009.

[30] Hetsroni G. Red., handbook of multiphase system. McGraw-Hill Book 
Company; 1982.

[31] Hewitt G, Shires G, Bott T. Process heat transfer. CRC Press, Begell House; 1994.

[32] Martinelli RC, Nelson DB. Prediction of pressure drop during forced circulation boiling of water. Trans Am Soc Mech Eng 1948;70(6):695-702.

[33] Dziubiński M, Prywer J. Two-phase fluid mechanics (in Polish). Warszawa: WNT; 2009.

[34] Fortran PowerStation 4.0. Microsoft developer studio. Palo Alto, CA: Microsoft Corporation; 1995.

[35] Zima W, Grądziel S. Simulation of transient processes in heating surfaces of power boilers. LAP LAMBERT Academic Publishing; 2013.

[36] Grądziel S. Heat load determination of boiler furnace chamber. Arch Combust 2015:35(No 2):75-88.

[37] Kuznetsov NW, Nitor WW, Dubovski IE, Karasina ES. Thermal calculations of steam boilers. Standard method (in Russian). Moscow, Russia: Energy; 1973.

\section{Nomenclature}

\author{
A: surface area, $\mathrm{m}^{2}$ \\ $d$ : diameter, $m$ \\ Fr: Freund number, dimensionless \\ $f$ : friction factor, dimensionless \\ g: gravitational acceleration, $\mathrm{m} / \mathrm{s}^{2}$ \\ G: mass flux, $\mathrm{kg} /\left(\mathrm{m}^{2} \mathrm{~s}\right)$ \\ $H$ : furnace chamber height, $m$ \\ $h$ : enthalpy, J/kg \\ $j$ : circulation multiplicity factor, dimensionless \\ MSE: mean-square error, dimensionless \\ $\dot{m}$ : mass flow, $\mathrm{kg} / \mathrm{s}$ \\ $p$ : pressure, $\mathrm{Pa}$
}

$q$ : heat flux, $\mathrm{W} / \mathrm{m}^{2}$

$R e$ : Reynolds number, dimensionless

$t$ : temperature, ${ }^{\circ} \mathrm{C}$

$U$ : perimeter, $\mathrm{m}$

$w$ : velocity, $\mathrm{m} / \mathrm{s}$

We: Weber number, dimensionless

$X$ : Martinelli parameter, dimensionless

$x$ : dryness factor, dimensionless

$z$ : axial coordinate, $\mathrm{m}$

Greek letters

$\Delta \tau$ : time step, $\mathrm{s}$

$\Delta z$ : control volume length, $\mathrm{m}$

$\eta$ : dynamic viscosity, $\mathrm{Pa} \cdot \mathrm{s}$

$\varphi$ : tube inclination angle, deg

$\phi$ : two-phase multiplier

$\rho$ : density, $\mathrm{kg} / \mathrm{m}^{3}$

$\tau$ : time, $\mathrm{s}$

Subscript

$f:$ friction

$G$ : gaseous

in: inner

$j$ : control volume number

$L$ : liquid

TP: two-phase 